\title{
Dedicated to James Earl Baumgartner
}

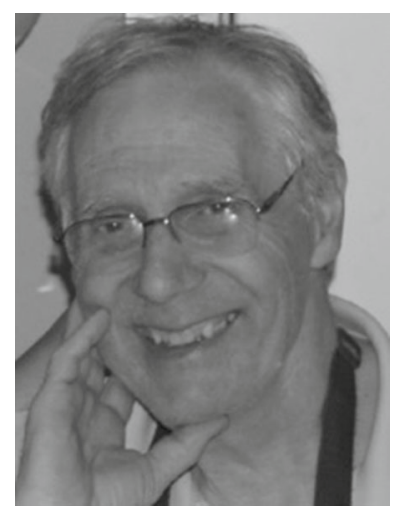

The editors, authors, and many of the readers of this volume knew Jim Baumgartner as a set-theorists' set-theorist. His work in the field will be remembered long after we are all gone. But Jim's contributions went well beyond the research he did, and Dartmouth was the perfect place for the special gifts that Jim had: an extraordinary ability as both an undergraduate teacher to the next generation of mathematician and as a thesis advisor to those about to enter the field, a brilliant lecturer and an inspiring mentor to young faculty (including a number of John Wesley Young instructors over the years), and a colleague and co-author of many of us. It was impossible not to like and admire Jim, and this volume is our chance to celebrate all that he was and did. 